\title{
SANKSI PIDANA TERHADAP WARGA NEGARA ASING YANG MELAKUKAN TINDAKAN PEMBOBOLAN ANJUNGAN TUNAI MANDIRI (ATM) DENGAN TEKNIK SKIMMING
}

\author{
Christin Dessy Natalia DE.F, A.A. Sagung Laksmi Dewi, I Made Minggu Widyantara \\ Fakultas IImu Hukum Universitas Warmadewa, Denpasar - Bali, Indonesia
}

\begin{abstract}
Abstrak
Tingkat kerawanan kejahatan di dunia maya (cyber crime) dewasa ini dan kerugiannya sudah melebihi dunia nyata. Cyber crime merupakan satu sisi gelap dari kemajuan teknologi yang mempunyai dampak negatif yang sangat luas bagi seluruh bidang kehidupan modern saat ini. Dampak yang akan dirasakan akibat dari ambruk atau hancurnya sebuah bank tidak hanya terbatas pada bank yang bersangkutan melainkan akan berdampak luas pada bank lain. Penelitian ini dilakukan dengan tujuan mengungkap penyebab terjadinya tindak pidana pembobolan mesin ATM dengan menggunakan teknik skimming berdasarkan UU No. 19 Tahun 2016 dan bagaimana pertanggungjawaban pidana terhadap pelaku tindak pidana pembobolan ATM dengan menggunakan teknik skimming berdasarkan UU No. 19 tahun 2016. Penelitian ini menggunakan metode penelitian hukum normatif. Hasil dari penelitian ini menunjukkan bahwa penyebab terjadinya tindak pidana pembobolan mesin ATM dengan teknik skimming adalah kelalaian dari pemilik kartu ATM itu sendiri. Pada kejahatan pembobolan ATM dengan cara skimming, korban biasanya tanpa sadar sudah direkam video pada saat memasukkan pin ATM dan pita magnetiknya sudah direkam melalui alat khusus. Pada hasil penelitian ini juga dikemukakan bahwa tindakan kejahatan pembobolan mesin ATM dengan teknik skimming dapat dijerat dengan Pasal $30 \mathrm{UU}$ ITE, sehingga aparat kepolisian telah mempunyai landasan hukum untuk mengambil tindakan penyelidikan dan penyidikan kejahatan kartu ATM dan transaksi elektronik lainnya.
\end{abstract}

Kata kunci: Tindak pidana; Skimming; Undang-undang No. 19 Tahun 2016

\begin{abstract}
The level of crime vulnerability in cyberspace (cybercrime) today and its impact has exceeded the real world. Cybercrime is a dark side of technological advances that have a very broad negative impact on all areas of modern life today. The impact that will be felt as a result of the collapse of a bank is not only limited to the bank concerned but will have a broad impact on other banks. This research was conducted with the aim of uncovering the causes of the crime of burglary using skimming techniques based on Law No. 19 of 2016 and the criminal responsibility of the perpetrators of criminal acts of ATM burglary using skimming techniques based on Law no. 19 of 2016. This research employed normative legal research methods. The results of this study showed that the cause of the crime of burglary using skimming techniques is the negligence of the owner of the ATM card. In the crime of skimming ATM burglary, unawarely the victim usually has been video recorded when inserting the ATM pin and the magnetic tape has been recorded through a special device. In the results of this study, it was also stated that the crime of burglary with ATM machines using skimming techniques could be charged under Article 30 of the ITE Law, so that police officers have a legal basis to take action to investigate ATM card crimes and other electronic transactions.
\end{abstract}

Keywords:Criminal Act; Skimming; Law No. 19 of 2016

\section{PENDAHULUAN}

Seluruh makhluk di dunia ini memiliki karunia ataupun kelebihan tersendiri, salah satu adalah penggunaan teknologi. Tuhan menciptakan umat manusia untuk dapat menggunakan fisiknya untuk hal-hal yang baru di antaranya adalah kemampuan untuk mengingat dan menyimpan memori atau data serta kelebihan untuk menghasilkan sesuatu dari data itu (Kusmana, 2015). Seiring dengan perkembangan tekonologi, telah diterbitkan peraturan UU No. 11 Tahun 2008 mengenai informasi dana transaksi melalui elektronik yang sering kita kenal dengan bentuk bayangan dari Pemerintah bersama DPR dengan kemungkinan hal terburuk yang akan ditimbulkan (Kaligis, 2012). 
Dewasa ini manusia dimanapun dan kapanpun menggunakan media elektronik untuk berkomunikasi atau melakukan hubungan interaksi. Dalam kehidupan nyata manusia berhubungan dengan menggunakan media teknologi seperti komputer, handphone, dan yang lainnya, dimana tanpa sadar manusia sedang berhubungan dengan banyak ancaman yang mengintai. Saat ini telah hadir satu rezim baru yang kami sebut SIBER Hukum. Hukum siber sering diartikan sebagai hukum cyber law, dimana saat sekarang ini secara Internasional digunakan oleh berbagai istilah hukum untuk permasalahan yang berkaitan dengan pemanfaatan teknologi informasi (Hasim, 2002).

Kemajuan berbagai ilmu teknologi (IPTEK) dan dilanjutkan dengan perkembangan zaman yang dewasa ini disebut dengan globalisasi membawa impresi yang luar biasa di seluruh penjuru muka bumi tanpa kecuali Indonesia yang merupakan Negara yang berkembang dengan penggunaan teknologi terbanyak. Progres yang terjadi saat ini banyak ditemui mencakup seluruh hal dalam kehidupan masyarakat dan bernegara yang salah satunya merupakan bidang perekonomian.

Hukum Teknologi Informasi atau Hukum dunia maya yang saat ini marak terjadi adalah kejahatan skimming yang merupakan hal pidana percurian terdapat dalam kitab undang-undang dan UU No. 19 Tahun 2016 mengenai Transaksi Elektronik yang saat ini disebut UU ITE. Semua orang penduduk saat ini telah memiliki kartu transaksi elektronik dari penduduk desa hingga kota. Jika disurvei dompet penduduk sebagian besar berisi kartu plastik yang disebut ATM (Anjungan Tunai Mandiri). Sangat mengejutkan ketika saat ini banyak terjadi pembobolan ATM yang semakin banyak menyerang nasabah bank terkemuka yang memunculkan banyak sekali kerugian yang nilainya mencapai milyaran (Pamuji, 2018).

Saat ini kita sudah tau banyak jenis barang teknologi seperti HP, Internet, Laptop dan yang lainnya. Dalam kehidupan saat ini penggunaannya teknologi canggih tersebut sangat efektif dan juga berdaya guna. Keberadaan Teknologi dapat memudahkan cara kita berkerja dan termasuk dalam hal melakukan transaksi. Atas terciptanya teknologi seperti ini kebutuhan kita dapat teratasi dengan gampang serta saat pengambilan uang kita sudah sangat dipermudah dengan mesin canggih yang disebut ATM yang tidak memakan banyak waktu. Namun, semakin meningkat nominal pengambilan uang di ATM tanpa kita ketahui kita semakin dekat dengan kejahatan.

Yang merupakan titik yang paling lemah dan tanpa kita sadari yang menjadi target kejahatan yakni pembobolan dengan cara skimming. Kejahatan ini adalah kejahatan yang melalui computer atau jaringan LAN computer dan salah satu tindakan kejahatan yang menjadi ancaman serius saat ini. Dengan kita memanfaatkan teknologi ini baik yang berbasis sistem computer atau yang lainnya, kita sebagai pengguna adalah korbannya (Enrick, 2019; Faridi, 2018).

Tindak pidana pembobolan ini yang menggunakan skimming membuat banyak pihak merugi bahkan sampai pemerintah mengeluarkan kas Negara. Dengan kata lain, hancurnya sebuah perbankan tidak cuma hanya berefek pada intasi itu melainkan banyak pihak yang terkena imbasnya dan bank lainnya bahkan merasakan efek yang sama terkait sistem keuangan dan sistem pembayaran dari negara yang bersangkutan serta sistem pembayaran dunia juga ikut merasakan efeknya (Ekawati, 2018).

Dari uraian pada latar belakang masalah tersebut, penelitian ini dilakukan dengan tujuan mengungkap penyebab terjadinya tindak pidana pembobolan mesin ATM dengan menggunakan teknik skimming berdasarkan UU No. 19 Tahun 2016 dan bagaimana pertanggungjawaban pidana terhadap pelaku tindak pidana pembobolan ATM dengan menggunakan Teknik skimming berdasarkan UU No. 19 Tahun 2016.

\section{METODE PENELITIAN}

Suatu karya ilmiah akan tersusun secara sistematis, mempunyai arah yang jelas serta pembahasannya teratur. Jadi, penelitian ini didesain dengan mengguunakan metode penelitian hukum normatif yang lebih fokus pada segi hukumnya dengan cara mengkaji dan meneliti peraturan perundangan-undangan yang berkaitan dengan pokok permasalahan yang diteliti (Soekanto \& Mamudji, 2007). Pendekatan masalah yang digunakan dalam penelitian ini adalah pendekatan perundang-undangan. Sumber bahan hukum yang digunakan adalah bahan hukum primer yaitu peraturan perundang- undangan, bahan hukum sekunder yaitu jurnal atau skripsi- skripsi yang berhubungan dengan permasalahan yang diteliti, dan bahan hukum tersier merupakan bahan hukum yang mendukung bahan hukum primer dan bahan hukum sekunder dengan memberikan pemahaman dan pengertian contohnya seperti kamus besar bahasa Indonesia ( KBBI). 
Teknik pengumpulan bahan hukum yang digunakan adalah studi kepustakaan atau studi dokumen, dimana teknik ini mempelajari, mencatat, dan membaca doktrin, catatan, literatur, perundang-undangan, jurnal, dan media internet yang berkaitan dengan pokok masalah yang berhubungan dengan masalah yang penulis teliti (Amirudin \& Asikin, 2010). Data yang sudah terkumpul dianalisis menggunakan metode kualitatif dan disajikan secara deskriptif.

\section{HASIL DAN PEMBAHASAN}

\section{Penyebab Terjadinya Tindak Pidana Pembobolan Mesin ATM dengan Menggunakan Teknik Skimming Berdasarkan UU No. 19 Tahun 2016}

Tindak kejahatan Skimming adalah satu diantara berbagai jenis kejahatan yang termasuk dalam kejahatan cyber crime. Secara garis kecil ataupun secara global, rekening korbannya biasanya dikendalikan dengan sistem magnetic stripe pada Kartu ATM tanpa legalitas ataupun secara resmi yang seharusnya hanya bisa dikendalikan oleh pihak bank yang bersangkutan yang berwenang agar bisa mengendalikan rekening seorang nasabahnya. Seorang pelaku kejahatan cyber crime sudah mempunyai ilmu yang lumayan tinggi dengan teknologinya sehingga kejahatan jenis ini sangat sulit untuk dibersihkan secara menyeluruh karena mereka sangat susah untuk dilacak.

Akibat dari perkembangan teknologi hingga saat ini hampir semua orang saat ini telah memiliki kartu transaksi elektronik dari penduduk desa hingga kota. Jika disurvei dompet penduduk sebagian besar berisi kartu plastik yang disebut ATM (Anjungan Tunai Mandiri). Sangat mengejutkan ketika saat ini banyak terjadi pembobolan ATM yang semakin banyak menyerang nasabah bank terkemuka, yang memunculkan banyak sekali kerugian yang nilainya mencapai milyaran.

Pembobolan mesin ATM menggunakan teknik skimming merupakan salah satu dari jenis tindak pidana yang melakukan aksinya yaitu melakukan perusakan terhadap sistem, dengan penyebaran sistem, dengan pemindahan suatu data menggunakan sistem, serta menghilangkan data secara illegal mengenai data yang dimiliki korban dikirim pada suatu ATM yang dimiliki oleh pelaku yang sudah direncanakan terlebih dahulu, maka data serta uang yang ada pada ATM korban akan bertindak ke rekening pelaku tersebut. Hal itu menunjukan bahwa pelaku sudah memiliki ilmu teknologi yang lumayan tinggi yang dimanfaatkan untuk melakukan suatu kejahatan.

Bank merupakan salah satu Lembaga keuangan yang terpenting bagi masyarakat dalam suatu negara. Dalam sistem perekonomian, terdapat Bank Umum dan Bank Perkreditan Rakyat, dimana Bank tersebut dijalankan dan dimiliki oleh negara ataupun oleh swasta. Selain itu, terdapat Bank Sentral yang berfungsi mengatur serta mengawasi sistem kerja semua Bank tersebut serta membantu mencapai tujuan ekonomi dalam meningkatkan pembangunan perekonomian nasional agar ekonomi masyarakat semakin adil dan merata.

Bank merupakan lembaga yang menerima simpanan giro, deposito, dan membayar atas dokumen yang tertarik pada satu orang atau lembaga tertentu, mendiskonto surat berharga, serta memberikan pinjaman dan menanamkan dananya dalam bentuk surat berharga. Bank dapat diartikan secara sederhana yaitu sebagai lembaga keuangan dimana kegiatan usahanya yaitu menghimpun dana dari masyarakat dan menyalurkan kembali dana itu kepada masyarakat serta memberikan jasajasa bank lainnya. Bank juga dapat diartikan sebagai badan usaha yang tugas pokoknya yaitu sebagai lembaga perantara keuangan (financial intermediaries), yang menyalurkan dana dari pihak yang kelebihan dana (surplus unit) kepada pihak yang membutuhkan dana atau kekurangan dana (deficit unit) pada waktu yang sudah ditentukan. Bank merupakan suatu lembaga yang menjadi jembatan bagi orang-orang yang ingin menyimpan uang lebihnya ataupun jembatan bagi orang yang memerlukan uang, ataupun suatu lembaga yang menjadi jembatan antar perseorangan yang ingin bertransaksi.

Keberadaan Teknologi dengan kebutuhan kita dapat memudahkan cara kita berkerja dan tidak cuma itu dalam hal melakukan transaksi. Atas terciptanya teknologi seperti ini kebutuhan kita dapat teratasi dengan mudah serta saat pengambilan uang kita sudah sangat dipermudah dengan mesin canggih yang disebut ATM yang tidak memakan banyak waktu. Tapi semakin meningkat nominalnya saat pengambilan uang di ATM yang tanpa kita ketahui kita semakin dekat dengan kejahatan.

Di antara semua bank yang ada terdapat satu bank pusat yang memantau sistem dari semua bank yang ada serta memberikan bantuan terhadap bank tersebut sebagai salah satu usaha untuk bisa mencapai target mengembangkan pembangunan perekonomian nasional, yaitu untuk membantu menyejahterakan masyarakat dan memberi keadilan baginya dalam ekonomi yang merata. 
Tindak kejahatan di dunia cyber crime, sanksinya diatur dalam Undang-undang informasi dan teknologi yang merupakan dasar agar pihak kepolisian bisa menindaklanjuti kejahatan cyber crime melalui kegiatan penyelidikan serta mengumpulkan bukti-bukti pada ATM dan transaksi elektronik yang lainnya. Seperti yang kita ketahui, transaksi adalah kegiatan yang dilakukan oleh dua orang atau lebih berdasarkan kesepakatan kedua belah pihak, sedangkan transaksi ATM adalah transaksi yang pada mesin ATM yang bertujuan menerima berbagai kemudahan dari jasa-jasa Bank. Transaksi ATM adalah proses terjadinya kegiatan keuangan dari pihak nasabah yang menggunakan fasilitas dan jasajasa yang diberikan oleh Bank dengan maksud mendapatkan kemudahan dari transaksi tersebut.

ATM merupakan sebuah kartu yang yang dibuat dan diterbitkan untuk seseorang dengan lembaga perbankan yang bersangkutan lewat Card Center kantor inti atau unit cabang kantor lainnya. ATM sampai sekarang telah berada pada titik operasional pelayanan dengan maksimal serta adalah salah satu bukti dari perubahan teknologi yang sudah berkembang.

Kejahatan skimming adalah kejahatan yang melalui komputer atau jaringan LAN komputer dan salah satu tindakan kejahatan yang menjadi ancaman serius saat ini. Dengan kita memanfaatkan teknologi ini dengan baik berbasis sistem computer atau salah satu cara berkomunikasi di era global ini yang dapat terlihat secara virtual dengan menggunakan kita sebagai pengguna adalah korbannya.

Terjadinya pembobolan ATM tidak lepas dari kelalaian dari pemilik kartu ATM itu sendiri. Pada kejahatan pembobolan ATM dengan cara skimming, korban tanpa sadar telah direkam video ketika memasukkan pin ATM dan pita magnetik sudah pula direkam melalui alat khusus. Tindak pidana pembobolan ini yang menggunakan skimming sebagai caranya yang sangat amat membuat banyak pihak merugi bahkan sampai pemerintah mengeluarkan kas Negara. Dengan kata lain, efek yang dimunculkan ayang kita rasakan akibat ambruk dan hancurnya sebuah perbankan tidak cuma hanya berefek pada instasi itu melainkan banyak pihak yang terkena imbasnya dan bank lainnya bahkan merasakan efek yang sama terkait sistem keuangan dan sistem pembayaran.

\section{Pertanggungjawaban Pidana terhadap Pelaku Tindak Pidana Pembobolan ATM dengan Menggunakan Teknik Skimming Berdasarkan UU No. 19 Tahun 2016}

Tindak pidana pembobolan mesin ATM dengan teknik skimming adalah salah satu jenis tindak pidana yang melakukan aksinya dengan melakukan perusakan terhadap sistem, dengan penyebaran sistem, dengan pemindahan suatu data menggunakan sistem, serta menghilangkan data secara illegal mengenai data yang dimiliki korban. Uang dan data korban terkirim dari rekening korban ke rekening pelaku. Hal itu menunjukkan bahwa pelaku sudah memiliki ilmu teknologi yang lumayan tinggi yang dimanfaatkan untuk melakukan suatu kejahatan. Kejahatan jenis skimming telah diatur pada UU Informasi dan Teknologi yang merupakan dasar bagi pihak kepolisian agar bisa menindaklanjuti pelakunya serta menyelidiki cara atau sistem yang digunakan oleh pelaku dalam melakukan aksinya tersebut.

Kejahatan skimming adalah kejahatan yang melalui komputer atau jaringan LAN komputer dan salah satu tindakan kejahatan yang menjadi ancaman serius saat ini. Dengan kita memanfaatkan teknologi ini baik berbasis sistem komputer atau teknologi bentuk lain, kita sebagai pengguna adalah korban.

Dengan berkembangnya teknologi tindakan kejahatan pembobolan yang menggunakan skimming sangat amat membuat banyak pihak merugi bahkan sampai pemerintah mengeluarkan kas Negara. Dengan kata lain, kejahatan ini tidak hanya berefek pada instasi itu melainkan banyak pihak yang terkena imbasanya dan bank lainnya bahkan merasakan efek yang sama pada terkait sistem keuangan serta sistem pembayaran dari negara yang bersangkutan ataupun sistem pembayaran dunia juga ikut merasakan efeknya. Oleh karena itu, kejahatan yang dilakukan untuk membobol mesin ATM dengan cara skimming bisa dijatuhi sanksi pada Pasal 30 UU ITE yang merupakan dasar yang digunakan oleh pihak kepolisian untuk menindaklanjuti pelaku skimmer.

\section{SIMPULAN DAN SARAN}

\section{Simpulan}

Berdasarkan hasil dan pembahasan di atas, ada beberapa simpulan yang dapat dibuat, yaitu: pertama, faktor yang menyebabkan terjadinya tindak pidana pembobolan mesin ATM dengan teknik skimming adalah kelalaian dari pemilik kartu ATM itu sendiri. Pada kejahatan pembobolan ATM dengan cara skimming korban biasanya tanpa sadar sudah direkam video pada saat memasukkan pin ATM dan pita 
magnetiknya sudah direkam melalui alat khusus. Setiap pengguna ATM seharusnya tetap menjaga kerahasiaan nomor PIN masing-masing agar tidak menjadi korban pembobolan ATM. Kedua, pertanggungjawaban pidana terhadap pelaku tindak pidana pembobolan ATM dengan menggunakan Teknik skimming, pelaku bisa dijatuhi sanksi pada Pasal 30 UU ITE yang merupakan dasar yang digunakan oleh pihak kepolisian untuk menindaklanjuti pelaku skimmer.

\section{Saran}

Ada beberapa saran yang perlu disampaikan kepada beberapa pihak berdasarkan hasil penelitian ini, yaitu: pertama, bagi nasabah sebaiknya lebih berhati-hati saat akan melakukan transaksi di bank ataupun ATM dengan menjaga privasi mengenai PIN ATM dan lainnya, kedua untuk pihak bank diharapkan bisa memperbaharui sistem pada saat ada nasabah yang melakukan transaksi atau pengecekan terhadap sistem secara berkala untuk menghindari adanya pencurian dana nasabah dengan teknik skimming, dan bagi para penegak hukum perlunya perubahan terhadap sanksi yang diberikan terhadap pelaku pembobolan mesin ATM dengan teknik skimming tersebut, dengan tujuan agar benarbenar memberikan efek jera terhadap para pelaku tersebut, sehingga orang yang ingin melakukan kejahatan tersebut merasa takut jika melakukan tindak pidana tersebut, artinya selain memberikan efek jera terhadap tersangka sanksi tersebut juga bisa berfungsi untuk mencegah terjadinya tindak pidana itu lagi.

\section{DAFTAR PUSTAKA}

Amirudin, \& Asikin, Z. (2010). Pengantar Metode Penelitian Hukum.

Ekawati, D. (2018). Perlindungan Hukum terhadap Nasabah Bank yang Dirugikan Akibat Kejahatan Skimming Ditinjau dari Perspektif Teknologi Informasi dan Perbankan. Unes Law Review, 1(2), 157-171.

Enrick, M. (2019). Pembobolan ATM Menggunakan Teknik Skimming Kaitannya dengan Pengajuan Restitusi. Jurist-Diction, 2(2), 555-580.

Faridi, M. K. (2018). Kejahatan Siber Dalam Bidang Perbankan. CyberSecurity Dan Forensik Digital, $1(2)(2), 57-61$.

Hasim, M. S. (2002). Mengenali Undang-Undang Media dan Siber. Utusan Publications \& Distributors Sdn Bhd.

Kaligis, O. C. (2012). Penerapan Undang-Undang No. 11 Tahun 2008 tentang Informasi dan Transaksi Elektronik.

Kusmana, S. (2015). Merancang Karya Tulis Ilmiah.

Pamuji, R. A. (2018). Perlindungan Hukum bagi Nasabah dan Tanggung Jawab Bank dalam Kasus Card Skimming. Jurnal Lex Renaissance, 3(1), 25-43.

Soekanto, S., \& Mamudji, S. (2007). Penelitian Hukum Normatif: Suatu Tinjauan Singkat. 